\title{
LUSOFONIA NO CINEMA
}

\author{
Benalva da Silva Vitorio
}

\begin{abstract}
RESUMo
Sonhar e escrever. Assim, comecei este artigo, no qual as lembranças me transportaram em uma viagem metafórica ao mundo do cinema para refletir sobre Migração e Lusofonia, contemplando os intrincados caminhos do processo de identidade e alteridade. Com apoio metodológico da Autoetnografia e da Análise de Discurso da Escola Francesa, a construção discursiva representa desenho da vida de imigrantes tecida por fios de pertenças. Assim, o filme luso-brasileiro Terra estrangeira, como objeto simbólico de análise, representa o entrelaçamento entre o desencanto no Brasil do Plano Collor e a esperança de sujeitos fronteiriços em Portugal, lusófonos na busca da concretização de seus sonhos.
\end{abstract}

\section{Palavras-chave}

Cinema; memória; migrações; lusofonia

\section{LUSOPHONY IN THE CINEMA}

\begin{abstract}
Dreaming and writing it, that was how I started this article in which the memories transported me on a metaphorical journey into the world of the cinema to reflect about Migration and Lusophony, contemplating the intricate paths of the process of identity and otherness. With the methodological support of Autoethnography and the French School of Discourse Analysis, the discursive construction represents the immigrant's life illustration starting from its origins. Also, as a symbolic object of analysis, the Luso-Brazilian movie Foreign land represents the interweaving between the Brazilians' disillusion with the Collor Plan and the hope of the Lusophones in the Portugal border and the quest of realizing their dreams.
\end{abstract}

\section{KEYWORDS}

Cinema; memory; migrations; Lusophony

Escrever é o mesmo processo do ato de sonhar: vão se formando imagens, cores, atos e, sobretudo, uma atmosfera de sonho que parece uma cor e não uma palavra. (Clarice Lispector, 2013, p. 5)

Depois de um sonho recorrente três noites seguidas, resolvi escrever este artigo, no qual procuro relacionar minha experiência de imigrante em dois países lusófonos 
com o eixo da situação vivida no devaneio noturno. Para tanto, a memória iluminou minhas reflexões para proceder à análise de um filme como objeto discursivo, a fim de compreender os processos de produção de sentidos e de constituição dos sujeitos em suas posições.

No sonho, como se estivesse em um filme, vejo-me às margens do rio Tejo, em Lisboa, ao lado do cineasta Glauber Rocha, conversando sobre cinema, identidade e alteridade. Em meio ao relato sobre nossos encantos e desencantos como imigrantes em Portugal, o voo raso das gaivotas sobre nossas cabeças sempre interrompia o encontro e eu acordava frustrada. Na terceira manhã, após o mesmo sonho, recorri à minha memória para refletir sobre os diferentes sentidos daquela conversa.

Do sonho às palavras lembrei-me de uma frase que marcou a minha época de estudante de Jornalismo, na década de 1960: "uma câmera na mão e uma ideia na cabeça". Assim, esse princípio que pautou o trabalho do baiano Glauber Rocha, cineasta, ator e escritor, inspirou-me a escrever esse texto com uma caneta na mão e muitas idéias na cabeça.

Ao desenvolver nova estética cinematográfica com Barravento (1961), filme diferente da produção norte-americana, Glauber Rocha "abria perspectivas novas para o cinema brasileiro, e isso não apenas porque surgia, com toda a evidência, um grande talento", como reconheceu Bernardet (1967, p. 52). Seu primeiro contato com o cinema foi na produção dos documentários O pátio (1959) e Cruz na praça (1960). Entre suas obras premiadas internacionalmente estão Deus e o diabo na terra do sol (1964) e Terra em transe (1967).

Estabelecendo interlocução entre os vários sentidos envolvidos nas produções do Cinema Brasileiro, Glauber Rocha tomou a noção de moderno como ponto de partida, influenciado por dois movimentos: Nouvelle Vague francês e neorrealismo italiano (Augusto, 2008; Marie, 1997). Assim, o cineasta brasileiro se aventurou na sétima arte de forma experimental, rompendo com a tradicional produção cinematográfica, dando origem ao Cinema Novo Brasileiro, na década de 1960, período que antecedeu o golpe militar de 1964 e se estendeu até a abertura política, no início da década de 1980, refletindo o contexto histórico do Brasil. Devido à sua estética cinematográfica com mensagem política revolucionária, foi perseguido pelo regime militar brasileiro e, em 1971, buscou exílio em Portugal.

Naquele ano, sai do Brasil e cheguei a Portugal pela primeira vez, embora meus motivos fossem diferentes das razões do cineasta brasileiro. Com as mãos vazias, mas com a concepção glauberiana de "uma ideia na cabeça", meu objetivo era refazer o processo identitário no espaço lusófono, que compreende Países de Língua Oficial Portuguesa (Mourão, 1994; Reis, 2005; Vitorio, 2006). Assim, 48 anos depois, rememoro meu percurso para refletir sobre cinema, identidade e alteridade, com base no método autoetnográfico e nos princípios e procedimentos da análise de discurso da Escola Francesa. Dessa forma, a partir da memória, a narrativa sobre minhas experiências a respeito da lusofonia tem como objetivo pensar o político em relação ao processo migratório no cinema, tomando como objeto de análise o filme Terra estrangeira de Walter Sales e 
Daniela Thomas. Portanto, a linha norteadora desse artigo está na reflexão, como ato que "expressa consciência de sua conexão necessária com a situação de pesquisa e, portanto, seus efeitos sobre o sujeito pesquisador" (Anderson, 2006, p. 382).

\section{LEMBRANÇAS}

Antes de recorrer à memória para "contemplar", no sentido de compreender, as lembranças, já que o tempo se encarregou de depositar muito da minha vivência no arquivo do esquecimento, procedo à reflexão sobre um conceito que gira em torno das migrações e que surtiu efeitos, teóricos e práticos, nos meus trabalhos de pesquisa. Trata-se da palavra refugiado, que se aplica de forma vaga e, muitas vezes, indevida.

Considero refugiado como categoria de imigrante, ou seja, situação daquele que emigra (sai do seu país de origem) por situação forçada, "em razão de fundados temores de perseguição devido à sua raça, religião, nacionalidade, associação a determinado grupo social ou opinião política", como define a Convenção das Nações Unidas relativa ao Estatuto dos Refugiados, conhecida como Convenção de Genebra, de 1951, no seu artigo $1^{\circ}$. Diante dessa situação, o sujeito emigra em busca de asilo e, quase sempre, sai do seu país de origem sem a devida preparação, inclusive sem documentação, a fim de se instalar em outro território.

Ao chegar ao país de destino, que nem sempre é país de acolhimento, como ultimamente se constata no noticiário internacional, o emigrante passa a ser imigrante e como tal, dependendo da situação que emigrou, é classificado, ou seja, recebe rótulos, sendo os mais comuns "indocumentado" e refugiado, de acordo com o jogo de interesses e conveniência das duas partes: do imigrante e dos órgãos oficiais do país de chegada. Tanto o primeiro rótulo quanto o segundo marcam o sujeito imigrante de tal forma que o marginalizam na sociedade em que se estabelece. Exemplo nesse sentido foi o desabafo de um dos entrevistados em minha pesquisa sobre imigrantes no meio universitário. Indignado, o senegalês foi incisivo em suas críticas ao considerar-se segregado, excluído na sala de aula, afirmando que, "para algumas pessoas, mesmo na universidade, refugiado é bandido" (Vitorio, 2018, p. 758).

No ano de 1977, tomei conhecimento em Lisboa que estava na "mira" do regime militar brasileiro, provavelmente devido à coluna que assinava sobre o Brasil, no semanário português Expresso. Naquele momento, poderia ter solicitado asilo em Portugal e, possivelmente, conseguiria o estatuto de refugiada. Porém, enfrentei a situação e, quando visitava minha família no Brasil, sentia a vigilância cerrada do regime político, passava por situação humilhante no aeroporto, mas não me interrogaram, nem me prenderam. Quando voltei a viver no Brasil, após a redemocratização no país, não quis tomar conhecimento sobre os motivos da perseguição e do processo político que me atribuíram, interferindo na minha carreira profissional, a partir do momento que resolvi emigrar.

Sendo assim, há que ter cautela ao atribuir categorias ao imigrante, considerando-se a subjetividade e até mesmo a "oportunidade" do requerente à concessão do status 
de refugiado. Assim, creio eu, evita-se a difusão de estereótipos do imigrante como vítima de mazelas, o que pode levá-lo tanto à situação de "protegido" em detrimento dos nacionais, quanto à situação de intolerância e até mesmo exclusão no meio que pretende ser acolhido em busca de uma vida mais estável (Vitorio, 2018, p. 753).

Dezembro de 1971. Lisboa, capital portuguesa. Daqueles meus tempos de estudante de Ciências Sociais e Política Ultramarina, lembro-me das mulheres vestidas de preto, carregando a tristeza no olhar. Mesmo formada em Jornalismo, não tinha conhecimento de que em Portugal, a exemplo do Brasil, se vivia as agruras da repressão, da censura e cerceamento da liberdade de expressão. Além disso, o país enfrentava a guerra nas suas colônias em África. Depois, veio a Revolução dos Cravos. Era abril de 1974. E Lisboa respirava a primavera, que iluminava Portugal e os caminhos para a independência das colônias no ultramar.

Julho de 1978. Maputo, antiga Lourenço Marques, capital de Moçambique. Naquele país africano, em meus tempos de cooperante, vivenciei as marcas da guerra, deixando o rastro de fome, miséria e a urgência para a reconstrução nacional. Lembro-me das crianças seminuas, carregando medo e curiosidade na beleza do olhar profundo.

Tempo e espaço configuram recordações em três continentes. Memória do recente processo histórico lusófono, construída na aprendizagem de vivência e de convivência em busca da identidade. Desterritorializada, a partir de 1971, eu aprendi com o Outro e com ele refiz a trajetória do meu processo identitário que, segundo Orlandi (1990, p. 122), "é constituído por uma falta (o diferente) e pelo desejo de completude (o mesmo)". Assim, assegura a autora, se constitui o movimento das identidades, o movimento das formações discursivas.

Para acompanhar esses movimentos, encontrei na autoetnografia a sustentação teórica como método na pesquisa sociológica que, para muitos estudiosos, fundamenta-se na experiência pessoal, a fim de sensibilizar os leitores para questões sobre identidade, para experiências envoltas pelo silêncio acadêmico referente a algumas questões sociais e "formas de representação que visam aprofundar a nossa capacidade de empatia com as pessoas que são diferentes de nós" (Adams, Bochner \& Ellis, 2011, p. 274).

Dimensão importante da autoetnografia, segundo Santos (2017, p. 224), é o reconhecimento de se compreender "como e por que" as identidades são importantes, por "incluir e interrogar" as experiências ligadas às diferenças socioculturais. Explica a sua posição, considerando que a autoetnografia consiste em "abordagem que reconhece e envolve a subjetividade, a emotividade e as perspectivas do pesquisador" sobre determinadas questões.

No percurso desse meu trabalho, com base na análise de discurso da Escola Francesa (Gadet \& Hak, 1997; Maldidier, 1994; Orlandi 1999; Pêcheux 1997), o dizer acionou a memória trabalhada em relação ao discurso, ou seja, a memória discursiva, como sendo "o saber discursivo que torna possível todo dizer e que retorna sob a forma do pré-construído, o já-dito que está na base do dizível, sustentando cada tomada da palavra" (Orlandi, 1999, p. 31). No jogo entre paráfrase e polissemia, entre o mesmo e o diferente, entre o já dito e o a se dizer, coloquei-me em movimento, traçando meu 
percurso, (me) significando, como Orlandi (1999, p. 36) considera a tensão em todo o discurso.

Nesse meu texto, a questão em causa é o percurso migratório, considerado como a grande problemática da atualidade e que, ultimamente, tenho trabalhado como objeto de pesquisa. Para tanto, ao relacionar cinema, identidade e alteridade, a recorrência à memória não foi tarefa fácil, como explica Mattelart (2005, p. 99).

O trabalho de memória não avança sem um trabalho de luto. É na relação entre a rememoração e a perda que se tornam possível o reconhecimento mútuo das culturas, a mútua reinterpretação das respectivas histórias e o trabalho sem fim de tradução de uma cultura em outra.

Nos dezessete anos ininterruptos como imigrante, sendo doze em Portugal e cinco em Moçambique, constatei a concepção de Mattelart (2005, p. 99), de que "a ideia do luto, transmitida pela psicanálise, supõe que não há tradução perfeita", mesmo se tratando da língua oficial entre países, como acontece na Comunidade dos Países de Língua Portuguesa - CPLP.

Embora reconheça que a "tradução de uma cultura em outra", nesse espaço geográfico, é "trabalho sem fim", acredito no esforço intelectual para "uma política fundada no reconhecimento da diversidade" para o desenvolvimento das "faculdades criadoras", tanto individuais quanto coletivas (Mattelart, 2005, p. 87).

Nas pesquisas que realizei sobre imigrantes brasileiros em Portugal (Vitorio, 2007, 2015) verifiquei o desencanto daqueles que esperavam encontrar no "país irmão" as facilidades da língua comum e dos laços históricos, considerando que podia se "instalar de armas e bagagens, sem mudar nada nos seus gestos e nos seus hábitos", como adverte Maalouf (1999, p. 51). Por outro lado, observei naqueles que, no encontro com - Outro, se adaptaram à Diferença, pautando a convivência ao "contrato moral", com base na reciprocidade, ou seja, no respeito mútuo. Nesse sentido, encontrei em Maalouf (1999, p. 55) o conselho que, instintivamente, pautei minha conduta como imigrante: caminhar com segurança na direção do Outro com os braços abertos e a cabeça erguida. Porém, esse autor adverte que só é possível abrir os braços se a cabeça estiver erguida. Assim, se constrói a identidade cultural, no contato com o Outro, com a alteridade, em vivências e convivências. Mas, nem todos os emigrantes se preparam devidamente ao deixar o país de origem para tentar a sorte em outro lugar, como imigrante. Ao fugir da desesperança, muitos esperam encontrar no Outro, no Diferente, apoio e aceitação na terra estrangeira.

\section{CASO EXEMPLAR}

Ao empreender a tarefa de leitura para a compreensão de como o objeto simbólico, no caso um filme, produz sentidos, lembrei-me das palavras de Chaui $(1994$, p. 21) de que "ler é retomar a reflexão de outrem como matéria prima para o trabalho de nossa própria reflexão". 
Nesse sentido, tomei como caso exemplar o filme luso-brasileiro Terra estrangeira, lançado em 1995, dirigido por Walter Salles e Daniela Thomas. A obra cinematográfica reflete os modos de representação da realidade, a partir de duas problemáticas enfrentadas pelos brasileiros, no começo da década de 90: a crise econômica e a decisão de emigrar. Como "fato discursivo", o texto fílmico trabalha a memória para a consideração dos elementos submetidos à análise, porque desperta lembranças de quem foi imigrante e ajuda a tecer consideração sobre identidade e alteridade como construção na relação com o Outro, o Diferente.

De acordo com Orlandi (1999, p. 72), o texto, como objeto simbólico, que oferece lugar à interpretação, é "espaço significante", ou seja, "lugar de jogo de sentidos, de trabalho da linguagem, de funcionamento da discursividade". Assim, explica o que considera ser a produção de novas práticas de leitura.

O analista tem de compreender como ele [o texto] produz sentidos, o que implica em saber tanto como ele pode ser lido, quanto como os sentidos estão nele. $\mathrm{Na}$ análise de discurso, não se toma o texto como ponto de partida absoluto (dadas as relações de sentidos) nem de chegada. Um texto é só uma peça de linguagem de um processo discursivo bem mais abrangente e é assim que deve ser considerado. Ele é um exemplar do discurso.

No contexto amplo de Terra estrangeira a narrativa parte do Brasil da época Collor para encontros em Portugal, terra de esperança de quem foge da "crise" no seu "país tropical". O enredo do filme compreende duas partes que se entrelaçam. A primeira, no Brasil, mais precisamente na cidade de São Paulo, onde mãe e filho alimentam sonhos, apesar da crise econômica decorrente do Plano Collor, que sucateou a economia do país e "confiscou" a poupança dos brasileiros. Paco, o filho, sonha em ser ator. Sua mãe Manuela, imigrante espanhola, sonha em voltar para San Sebastian, sua terra natal. Com a morte da mãe, Paco tenta realizar o sonho materno. Embarca para Portugal, aceitando levar contrabando na bagagem. Assim, a segunda parte do filme transcorre em Lisboa.

Salles e Thomas, portanto, traçam o perfil do cotidiano dos brasileiros, no início dos anos 90, marcados pela decepção político-econômica de perdas, materiais e afetivas. Como alternativa para fugir da crise, a partida para o exterior em busca de vida melhor traçou o destino de muitos brasileiros. De um país de imigração, o Brasil, então, se tornou um país de emigração.

Ao partir, o emigrado rejeita algumas coisas. No caso de Terra estrangeira, a rejeição de Paco tem origem na determinação político-econômica do governo de Fernando Collor de Mello (1990-1992). Rejeição acompanhada do sentimento de perda (da mãe, da poupança, do sonho de ser ator), de saudades, de recordações. O encontro em Lisboa marca o estatuto do migrante. A capital portuguesa, portanto, passa a ser o foco da ação no filme, foco da narrativa, da história, da problemática dos imigrantes, daqueles que chegam a Portugal: brasileiros e africanos dos países de língua oficial comum, oriundos das ex-colônias. 
As marcas da lusofonia aparecem na música: MPB, marrabenta, morna, coladeira e até o fado, porque o português também é migrante. Assim, a problemática do filme representa a busca do Eu e do Outro; o encontro com as Diferenças; a procura para entregas, materiais e afetivas; a ruptura de fronteiras e de valores. A problemática, portanto, está no conflito da identidade lusófona, decorrente do contexto político-econômico da década de 90: Brasil do Plano Collor, que saqueou a poupança dos nacionais; África lusófona da pós-descolonização, da reconstrução nacional, dos confrontos armados internamente; Portugal da União Europeia, que rompeu com a filosofia salazarista do "orgulhosamente só de costas para a Europa".

A lusofonia que se constrói e se transforma na narrativa de Terra estrangeira pontua as pertenças múltiplas, a partir de um lugar: a cidade de Lisboa, que representou e representa a saída dos portugueses para o mundo, a entrada dos outros lusófonos na "Europa Fortaleza". Lugar, no imaginário de brasileiros e africanos, que representa a esperança para o reinício de vida e realizações. Lisboa, portanto, como lugar de encontro e despedida.

Contudo, a lusofonia não representa "um documento de identidade", porque, segundo Maalouf (1999, p. 18), a identidade de uma pessoa é constituída por uma série de elementos, "que não se limitam evidentemente aos que figuram nos registros oficiais".

Ao considerar "a riqueza" de cada pessoa como "um ser singular e potencialmente insubstituível", Maalouf (1999, pp. 18-19) aponta alguns elementos que constituem a identidade do sujeito:

a pertença a uma tradição religiosa; a uma nacionalidade, por vezes a duas; a um grupo étnico ou linguístico; a uma família mais ou menos alargada; a uma profissão; a uma instituição; a um determinado meio social... Mas a lista é bem mais extensa e virtualmente ilimitada; pode sentir-se uma pertença mais ou menos forte a uma província, a uma aldeia, a um bairro, a um clã, a uma equipa desportiva ou profissional, a um grupo de amigos, a uma empresa, a um partido, a uma associação, a uma comunidade de pessoas que partilham as mesmas paixões, as mesmas preferências sexuais, as mesmas diminuições físicas, ou que se acham confrontadas com os mesmos problemas.

Essas e outras pertenças constituem a personalidade, "os genes da alma", que na maior parte não são inatos. Já a identidade, que faz com que uma pessoa não seja idêntica a outra, é construída e transformada ao longo da existência humana. A identidade é formada por pertenças múltiplas, de forma una e vivida como um todo, a exemplo da cor da pele, da religião, da língua, da classe social. Geralmente, as pessoas se identificam com a pertença mais atacada, com aquela que está em causa e invade toda a identidade: "os que partilham com essas pertenças sentem-se solidários, reúnem-se, mobilizam-se, encorajam-se reciprocamente, colocam-se juntos contra os do outro lado". Assim, para Maalouf (1999, p. 36), "afirmar a sua identidade" torna-se forçosamente um ato de coragem, um ato libertador. 
Em Terra estrangeira, compreendo o sentido da lusofonia como construção/reconstrução da identidade. Busca e encontro como ato de coragem, como libertação de diferentes formas. Ao atravessar fronteiras - por mar, por terra, pelo ar - o lusófono pode encalhar em praia deserta, pode chegar ao outro lado ferido, ensangüentado, na busca de diferentes objetivos. É o caso dos nacionais dos Países Africanos de Língua Oficial Portuguesa - PALOP - e dos brasileiros, no período após a Revolução dos Cravos, em Portugal. No filme, Lisboa é o ponto de passagem, representado parcialmente no Caís do Sodré. O sonho de chegada está na representação de San Sebastian, que não é somente a Espanha, sonho português do desenvolvimento na Península Ibérica, rivalidade no passado entre regimes autoritários (salazarismo e franquismo). San Sebastian é a coragem basca de afirmação de um povo, de uma identidade política, lingüística, nacional.

No corpus do discurso entre Miguel (brasileiro, músico, contrabandista) e Pedro (o português, a ancoragem, o elo entre personagens) compreendo a representação de Portugal na Europa:

$$
\begin{aligned}
& \text { - A gente te manda um cartão postal da Europa (Miguel) } \\
& \text { - Primeiro, veja se consegue entrar na Europa (Pedro) (Terra estrangeira, 1996) }
\end{aligned}
$$

E eles conversam em Lisboa, como se Portugal não fizesse parte da Europa.

Outro sentido da lusofonia, como ato de coragem, de libertação, marcando uma das pertenças, está no desabafo de Alex (a brasileira garçonete e parceira de Miguel): "minha voz é uma ofensa para o ouvido deles" (Terra estrangeira, 1996). A constatação do sotaque na mesma língua oficial marca a diferença na Comunidade Lusófona. Além do sotaque, nesse espaço circulam sentidos diferentes às mesmas palavras; circulam línguas nacionais e dialetos sem reconhecimento oficial, mas que proporcionam a comunicação entre nacionais dos PALOP.

Da mesma forma, Salles e Thomas levantam no filme a questão da cor da pele e a acentuação da diferença: "não preste atenção aos pretos. Eles não têm nada a ver connosco" (Terra estrangeira, 1996). Na observação do português, funcionário da Pousada Imigrante, transparece a formação ideológica: "eles são os africanos, os pretos, os serviçais; nós, os portugueses, os colonizadores" (Terra estrangeira, 1996).

Compreendo, assim, o atravessamento da fratura étnica e lingüística que se confrontam permanentemente na comunidade lusófona. Exemplo nesse sentido está na formação discursiva de livros didáticos, no Brasil, onde fatos referentes à História Colonial refletem visões racistas e preconceituosas (Vitorio, 2006, pp. 156-157). De forma explícita, quem relatou o "encontro" entre alóctones e autóctones, no período da "descoberta" e da colonização, destacou a beleza natural da terra e suas riquezas econômicas. Porém, de forma implícita, nesse relato transparece o conflito cultural entre Nós e os Outros e a conveniência das alianças, dependendo do contexto.

No contexto das décadas de 1970 a 1990, os brasileiros foram bem-vindos em Portugal. Porém, foram rechaçados na primeira década do Século XXI por vários motivos, entre os quais a ameaça à afirmação de Portugal na União Europeia, decorrente da onda migratória no espaço geográfico, que ficou conhecido metaforicamente como "Europa Fortaleza". 
No filme Terra estrangeira as metáforas permeiam os modos de representação da realidade, entre as quais destaco quatro elementos significativos ao mundo da lusofonia: água, pertença, gênero e comunicação, que, de acordo com meu procedimento analítico, constituem efeitos metafóricos.

Ao definir efeito metafórico, Orlandi (1999, p. 78) considera que o mesmo permite colocar em relação discurso e língua, com objetivo na análise de compreender "o modo de articulação entre estrutura e acontecimento". Assim, a metáfora, de acordo com a sua concepção, "é constitutiva do processo mesmo de produção de sentido e da constituição do sujeito (...), vista como transferência, trabalho produzido pelo deslize (a deriva), pelo efeito metafórico, lugar da interpretação e da historicidade" (Orlandi, 1999, p. 78). Em Terra estrangeira observo o efeito metafórico nos quatro elementos referidos acima como produção de sentidos, processo sujeito ao deslize.

A água, que marcou a expansão portuguesa pelo mundo, aparece no filme em diferentes circunstâncias. No momento em que Paco toma banho para lavar a tristeza, a dor, a perda, inundando o banheiro do seu apartamento de classe média paulistana, - lugar de referência familiar; no suor do rosto de Paco, representando o seu esforço para afirmar-se profissionalmente como ator; na poça da calçada como restos: da chuva, do desânimo, da incapacidade de realização, da desilusão brasileira para com a redemocratização do país; nos encontros entre Alex e Paco, no Cabo da Roca, alusão à partida dos portugueses pelos mares; no barco encalhado na praia, significando que a água tanto pode libertar quanto aprisionar imigrantes, sejam lusófonos ou de qualquer comunidade.

De forma metafórica, a pertença lusófona aparece no violino: o disfarce na música como meio para transportar o ilícito. O contrabando da riqueza da terra (diamante de Angola) ironicamente é "entregue" ao povo (o mendigo), que não vê/reconhece a pedra valiosa e ela acaba sendo pisoteada pelos transeuntes. Por isso, a esperança é arrancada da alma imigrante, que tenta resistir à solidão, encontrar os companheiros de exílio, vencer a travessia.

Como referência metafórica, compreendo o gênero em dois personagens. De forma híbrida, masculino e feminino explodem em Alex que representa a ligação, o elo amoroso entre personagens. Já Igor, símbolo da masculinidade, estabelece a relação dos interesses econômicos entre América, África e Europa: o diamante como exploração, contrabando, mundo dos negócios permeado pela corrupção.

Por último, a metáfora da comunicação representada por um dos meios de comunicação social mais popular nos três contextos: Brasil, Portugal e os países africanos de expressão portuguesa. A televisão anuncia o Plano Collor, que exterminou o sonho de muitos brasileiros. A notícia sobre o "confisco" da poupança pelos bancos marca o fim da esperança da imigrante espanhola para o reencontro com a família em San Sebastian e a introdução de seu filho na Comunidade Europeia. O canal de televisão sai do ar, a telespectadora tomba morta no sofá da sala. Final da programação, final de vida, morte dos sonhos. Fim que marca a partida, a emigração, o recomeçar em Terra estrangeira. E o cinema relata os modos de representação da realidade lusófona. 
Nos últimos anos, circulando entre Brasil, Portugal e Moçambique, aprendi que, muito mais que língua oficial comum, a lusofonia representa o mosaico da diversidade cultural, conjugando tempo e espaço, a partir da mitologia dos navegadores. E um dos traços constantes de toda mitologia, segundo Roland Barthes (1957, p. 44), "é a impotência para imaginar o Outro". Diante do estranho, afirma o autor, "a Ordem conhece apenas duas condutas", que representam duas mutilações: ou se reconhece o Outro como simples marionete ou tenta-se neutralizá-lo "como puro reflexo do Ocidente". Barthes, portanto, considera que, na concepção da mitologia, o essencial é subtrair a história do Outro, porque, explica, "o mito se orienta pela mais forte das apropriações, a da identidade".

Como a identidade, no meu entender, resulta na relação entre Nós e os Outros, contemplando a Diferença, os lusófonos carecem de conhecimento recíproco das nossas histórias, de derrotas e de vitórias, que integradas representam a possibilidade de se avançar para o desenvolvimento conjunto de povos nos quatro continentes (África, América, Ásia e Europa), onde se pretende construir o patamar comum com base na lusofonia.

Para tanto, na minha concepção, é preciso compreender quem somos: Nós e os Outros, lusófonos dispersos pelo mundo representados na Comunidade dos Países de Língua Portuguesa: República de Angola, República Federativa do Brasil, República de Cabo Verde, República da Guiné-Bissau, República da Guiné Equatorial, República de Moçambique, República Portuguesa, República Democrática de São Tomé e Príncipe, República Democrática do Timor-Leste.

O caminho proposto consiste em viagens, reais e metafóricas (Ianni, 2000), despregadas dos mitos fundadores, ou a partir dos mesmos, para desconstruir e reconstruir a nossa história lusófona, sem medo do confronto com as Diferenças. Se a viagem real implica gastos na travessia dos oceanos para estar com o Outro, a viagem metafórica pode ser empreendida por meio de textos produzidos por instituições responsáveis na difusão do conhecimento, a exemplo da Mídia e da Escola.

Como brasileira que realiza viagens, reais e metafóricas, sobretudo no espaço lusófono, nunca regresso como a mesma pessoa que partiu. No percurso, observei que o candomblé brasileiro tem muito das danças tradicionais moçambicanas, que os brasileiros carregam a tristeza do fado em algumas variações da MPB, que o tempero da comida baiana lembra o sabor da matapa, prato típico moçambicano. Fui considerada indiana e cabrita, em Lisboa, após a "Revolução dos Cravos" em Portugal. Quase apanhei em Maputo, porque como negra não poderia estar na fila dos estrangeiros brancos (os cooperantes) para comprar o quilo de carne a que tinha direito como cota semanal. A minha brasilidade, assim, fundiu-se no hibridismo e tornei-me outra, cidadã do mundo lusófono.

Considero que a transformação deve-se à minha pertença à área da Comunicação Social, em que a curiosidade impulsiona o conhecimento, motiva investigações e pautas, ultrapassando as clássicas perguntas do lead. Acredito, defendo e pratico a intersecção entre Mídia e Escola para o exercício do conhecimento, sobretudo no nosso mundo 
lusófono, carente do processo de educação e com amplas possibilidades de agregar esforços e proporcionar o conhecimento sobre nossa história, nossa geografia e nossas culturas.

Entendo a cultura como uma produção, a exemplo do que Hall (2003, p. 44) explicita muito bem, porque ela "não é uma questão de ontologia, de ser, mas de se tornar", de se produzir em novo sujeito. No universo da lusofonia, a diversidade cultural permite a transformação do sujeito, na medida em que se promovam os espaços para o encontro entre Nós e os Outros, compreendendo e respeitando a Diferença.

Mas, nem sempre isso acontece, como observei nas pesquisas realizadas em Portugal, onde constatei que os meios de comunicação difundiam estereótipos sobre a identidade brasileira, principalmente as mulheres (Vitorio, 2007).

Em minha pesquisa do primeiro pós-doutorado sobre a identidade cultural dos imigrantes brasileiros em Portugal trabalhei com dois jornais portugueses de circulação nacional: Público e Jornal de Notícias, edições referentes aos meses de janeiro a dezembro de 2003. Naquele ano emblemático para os imigrantes brasileiros, constatei que fomos, em Portugal, o estereótipo das tangas penduradas no varal, das "meninas" de programa nas casas de alterne, da "galera" barulhenta vigiada por aparato policial. Enquanto lusófonos, fomos não-europeus em Portugal, os "ilegais" perigosos que desembarcavam no aeroporto de Lisboa na ilusão de encontrar abrigo no mitológico "país irmão". E no espaço da mídia portuguesa protagonizamos as histórias de "caça a ilegais", de repatriação humilhante, o que traduzia o desconhecimento de uns em relação aos outros, o desrespeito à diferença que marca a nossa identidade lusófona.

Lembro-me, assim, das palavras de Silva (2000, p. 82):

a afirmação da identidade e a marcação da diferença implicam, sempre, as operações de incluir e de excluir (...), dizer "o que somos" significa também dizer "o que não somos" (...). A identidade está sempre ligada a uma forte separação entre "nós" e "eles" (...), afirmam e reafirmam relações de poder (...), indicam posições de sujeito fortemente marcadas por relações de poder.

Essas relações de poder permeiam a lusofonia: poder da língua oficial (o Português) em detrimento a tantas línguas nacionais e dialetos. Poder da comunicação para estreitar os laços entre nações de quatro continentes. Poder da diversidade cultural que constitui o hibridismo como marca da nossa identidade. E, aqui e agora, o poder da memória, por meio dessa viagem metafórica. No percurso da viagem, como lembrou lanni (2000, p. 25) "a inquietação e a interrogação caminham juntas, sempre correndo o risco de encontrar o óbvio ou o insólito, o novo ou o fascinante, o outro ou o eu". E o cinema, como modo de representação da realidade, promove viagens para o encontro, em que memória e diversidade cultural abrem perspectivas para a lusofonia.

Breve estarei em Portugal. Como faço sempre, andarei nas margens do rio Tejo para contemplar o por do sol. Sei que não encontrarei Glauber Rocha, que faleceu em 1981. Mas, espero rever as gaivotas para rememorar o meu sonho interrompido e, talvez, 
esboçar o roteiro de um filme em "terra estrangeira", onde me considero familiar. Com essa ideia na cabeça, fugindo de pretensão conclusiva, deixo aos leitores, sejam eles emigrantes ou imigrantes, a possibilidade de construir o futuro discursivo dessas minhas reflexões.

\section{REFERÊNCIAS}

Adams, T., Bochner, A. \& Ellis, C. (2011). Autoethnography: an overview. Historical Social Research, 36, 273290. https://doi.org/10.2307/23032294

Anderson, L. (2006). Analytic autoethnography. Journal of contemporary Ethnography, 35, 373-395. https://doi. org/10.1177/0891241605280449

Augusto, I. R. (2008). Neo-realismo e Cinema Novo: a influência do neo-realismo italiano na cinematografia brasileira dos anos 1960. Intercom - Revista Brasileira de Ciências da Comunicação, 31(2), 139-163.

Barthes, R. (2003). Mitologias. Rio de Janeiro: Difel.

Bernardet, J. C. (1967). Brasil em tempo de cinema: ensaio sobre o cinema brasileiro de 1958 a 1966. Rio de Janeiro: Editora Civilização Brasileira.

Chauí, M. (1994). Os trabalhos da memória. In E. Bossi (Ed.), Memória e sociedade: lembranças de velhos (pp. 17-33). São Paulo: Companhia das Letras.

Gadet, F. \& Hak, T. (Eds.) (1997). Por uma análise automática do discurso: uma introdução à obra de Michel Pêcheux. Campinas/SP: Unicamp.

Hall, S. (2003). Da diáspora: identidades e mediações culturais. Belo Horizonte: UFMG.

Ianni, O. (2000). Enigmas da modernidade-mundo. Rio de Janeiro: Civilização Brasileira.

Lispector, C. (2013). As palavras. Rio de Janeiro: Rocco.

Maalouf, A. (1999). As identidades assassinas. Alges: Difel.

Maldidier, D. (1994). Elementos para uma história da análise do discurso na França. In E. P. Orlandi (Ed.), Gestos de leitura: da história no discurso (pp. 7-14). Campinas, SP: Unicamp.

Marie, M. (1997). La Nouvelle Vague, une école artistique. Paris: Nathan Cinema.

Mattelart, A. (2005). Diversidade cultural e mundialização. São Paulo: Parábola.

Mourão, F. A. A. (1994). A CPLP num mundo globalizado. Jornal de Letras, 628, 9-22.

Orlandi, E. (1990). "Terra à vista": discurso do confronto: velho e novo mundo. São Paulo: Cortez.

Orlandi, E. (1999). Análise de Discurso: princípios e procedimentos. Campinas, SP: Pontes.

Pêcheux, M, (1997). Análise de discurso: três épocas. In F. Gadet \& T. Hak (Eds.), Por uma análise automática do discurso: uma introdução à obra de Michel Pêcheux. Campinas: Unicamp.

Reis, C. (2005). A imagem portuguesa e o princípio da globalização: fronteiras e instrumentos estratégicos. Via Latina Ad Libitum: espaços lusófonos, 2(VI), 35-46. Coimbra: PMS.

Rocha, G. [Realizador] (1959). O Pátio [Filme]. Bahia. 
Rocha, G. [Realizador] (1960). Cruz na praça [Filme]. Salvador: Iglu Filmes.

Rocha, G. [Realizador] (1964). Deus e o Diabo na terra do sol [Filme]. Rio de Janeiro: Copacabana Filmes.

Rocha, G. [Realizador] (1967). Terra em transe [Filme]. Rio de Janeiro: Mapa Produções Cinematográficas Ltda.

Salles, W. \& Thomas, D. [Realizadores] (1995). Terra estrangeira [Filme]. São Paulo/ Lisboa: Flávio Tambellini, Paulo Dantas e Movie-Art, Antônio da Cunha Telles e Maria João Mayer.

Santos, S. M. A. (2017). O método da autoetnografia na pesquisa sociológica: atores, perspectivas e desafios. Revista do Programa de Pós-Graduação em Sociologia da USP, 24.1, 214-141.

Silva, T. T. (2000). A produção social da identidade e a diferença. In T. T. Silva, S. Hall \& K. Woodward (Eds.), Identidade e diferença: a perspectiva dos Estudos Culturais (pp. 73-102). Petrópolis: Vozes.

Vitorio, B. (2006). Ficção televisiva para o conhecimento da lusofonia. In M. L. Martins, H. Sousa \& R. Cabecinhas (Eds.), Comunicação e lusofonia: para uma abordagem crítica da cultura e dos media (pp. 155164). Porto: Campo das Letras.

Vitorio, B. (2007). Imigração brasileira em Portugal: identidade e perspectivas. São Paulo: Leopoldianum.

Vitorio, B. (2015). Imigrantes brasileiros e a crise em Portugal. São Paulo: Leopoldianum.

Vitorio, B. (2018). O imigrante no meio acadêmico: estudo de caso. In M. I. V. Lopes, N. Ribeiro, G. Castro \& C. D. Burnay (Eds.), Anais do XV Congresso IBERCOM 2017: -comunicação, diversidade e tolerância (pp. 746-764). São Paulo/Lisboa: ECA-USP/FCH-UCP. Retirado de http://assibercom.org/ebookibercom-2017.pdf

\section{NOTA BIOGRÁFICA}

Benalva Vitorio é Bacharel em Jornalismo, Doutorada em Ciências da Comunicação, Pós-Doutorada em Imigração. Professora dos cursos de Enfermagem, Jornalismo, Nutrição e Relações Internacionais. Coordenadora e professora do Curso de Extensão para a Terceira Idade. Líder do Grupo de Pesquisa Comunicação e Cidadania.

Email: benalvad@yahoo.com.br; benalva@unisantos.br

Morada: Universidade Católica de Santos, Rua Dr. Carvalho de Mendonça, 140 Santos/SP, Brasil

\section{Submetido: 16-06-2018}

Aceite: 05-02-2019 